NREL Evaluates the

Thermal Performance

of Uninsulated Walls to

Improve the Accuracy

of Building Energy

\section{Simulation Tools}

Researchers at the National Renewable Energy Laboratory (NREL) have developed models for evaluating the thermal performance of walls in existing homes that will improve the accuracy of building energy simulation tools when predicting potential energy savings of existing homes. Uninsulated walls are typical in older homes where the wall cavities were not insulated during construction or where the insulating material has settled. Accurate calculation of heat transfer through building enclosures will help determine the benefit of energy efficiency upgrades in order to reduce energy consumption in older American homes.
NREL performed detailed computational fluid dynamics (CFD) analysis to quantify the energy loss/gain through the walls and to visualize different airflow regimes within the uninsulated cavities. The effects of ambient outdoor temperature, radiative properties of building materials, and insulation level were investigated. The study showed that multi-dimensional airflows occur in walls with uninsulated cavities and that the thermal resistance is a function of the outdoor temperature-an effect not accounted for in existing building energy simulation tools.

The study quantified the difference between CFD prediction and the approach currently used in building energy simulation tools over a wide range of conditions. For example, researchers found that CFD predicted lower heating loads and slightly higher cooling loads. Implementation of CFD results into building energy simulation tools such as DOE2 and EnergyPlus will likely reduce the predicted heating load of homes.

\section{Key Research Results}

\section{Achievement}

NREL developed CFD models of uninsulated wall assemblies that help to improve the accuracy of building energy simulation tools when modeling potential energy savings in older homes.

\section{Result}

The study provides correlations for the resistance of the uninsulated assemblies that can be implemented into building simulation tools to increase accuracy of energy use estimates in older homes, which are currently over-predicted.

\section{Benefit}

Accurate estimates of the thermal characteristics of uninsulated assemblies will reduce the pre-retrofit performance errors and help predict retrofit energy savings.

\section{Funding Support}

This research was sponsored by the U.S. Department of Energy's Buildings Program. 


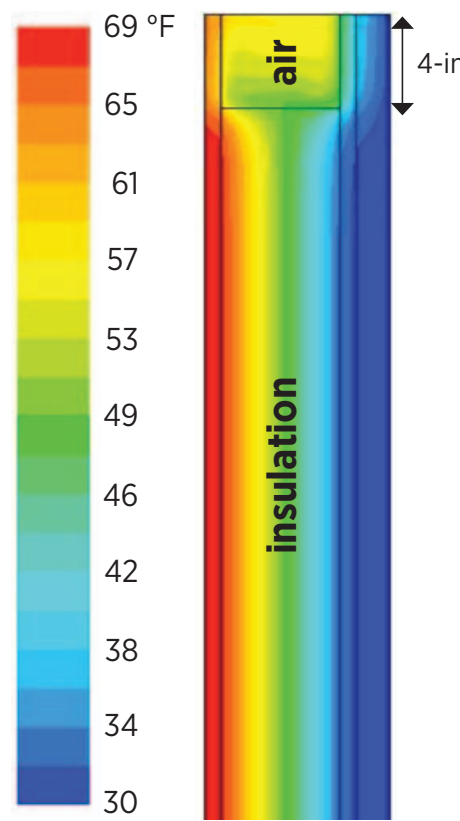

(a)

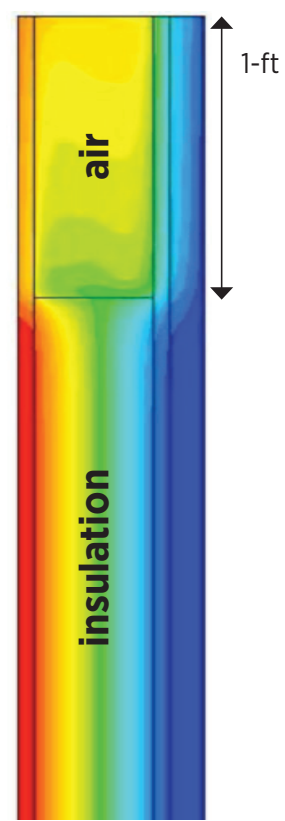

(b)

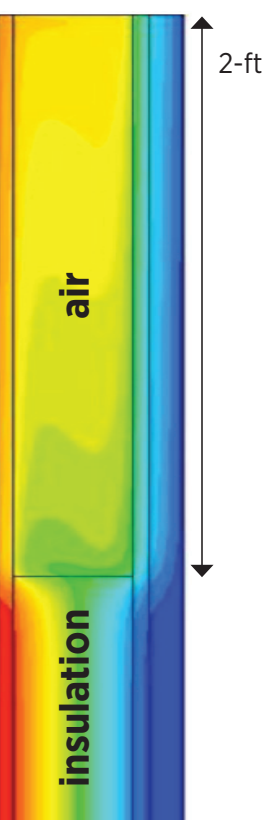

(c)

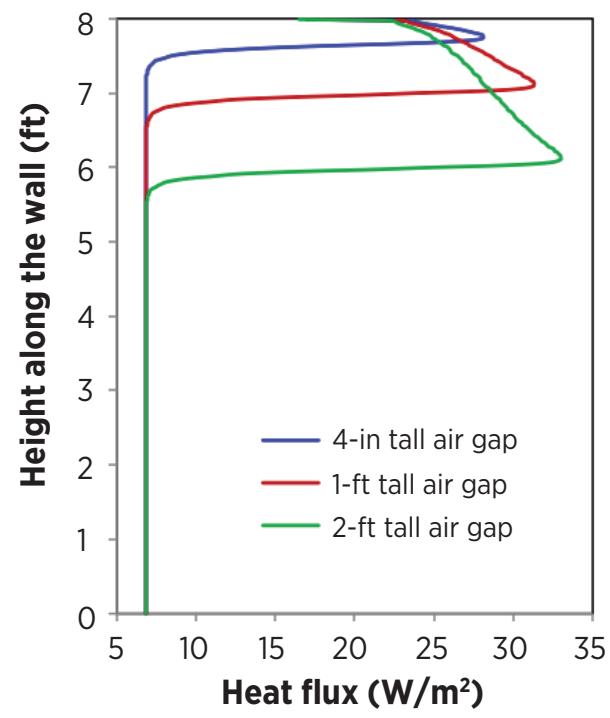

(d)

Figure 1. (a-c): Temperature distribution in the upper section of a partially insulated wall cavity. (a) 4-in. tall air gap, (b) 1-ft tall air gap, and (c) 2-ft tall air gap. (d): Heat flux along the inner surface of the wall exchanging heat with the room air. These results are for $70^{\circ} \mathrm{F}$ indoor temperature and $30^{\circ} \mathrm{F}$ ambient temperature. Figures by El Hassan Ridouane

Researchers also determined that a small air gap in a partially insulated cavity can lead to a significant reduction in thermal resistance. For instance, a 4-in. tall air gap (Figure 1a) led to a $15 \%$ reduction in resistance. Similarly, a 2-ft tall air gap (Figure 1c) led to $54 \%$ reduction in thermal resistance.

NREL researchers plan to extend this study to include additional wall configurations, and also to evaluate the performance of attic spaces with different insulation levels.
NREL's objective is to address each potential issue that leads to inaccuracies in building energy simulation tools to improve the predictions.

\section{For more information}

Ridouane, E.H.; Bianchi, M.V.A. (2011) "Thermal Performance of Uninsulated and Partially Filled Wall Cavities." Presented at the ASHRAE Annual Conference, Montreal, Quebec, June 25-29, 2011. NREL Report No. CP-5500-50925. www.nrel.gov/docs/fy17osti/50925.pdf.
Ridouane, E.H.; Bianchi, M.V.A. (2011). "Three-Dimensional Numerical Evaluation of Thermal Performance of Uninsulated Wall Assemblies." Presented at the ASME 2011 International Mechanical Engineering Congress and Exposition, Denver, Colorado, November 11-17, 2011. NREL Report No. CP-5500-52389 www.nrel.gov/docs/fy12osti/52389.pdf.

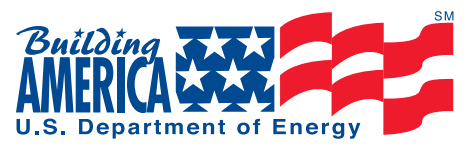
Renewable Energy
Prepared by the National Renewable Energy Laboratory (NREL), a national laboratory of the U.S. Department of Energy, Office of Energy Efficiency and Renewable Energy; NREL is operated by the Alliance for Sustainable Energy, LLC. 